Revista Complutense de Educación

ISSNe: 1988-2793

http://dx.doi.org/10.5209/RCED.60182

\title{
Evolución y Perspectivas de la Educación Moral
}

Autores: Juan Luis Fuentes (Ed.)

Editorial: Revista Española de Pedagogía

Año de publicación: 2018

$N^{\circ}$ de páginas: 126

ISBN: 978-84-16602-90-2

Dentro del ámbito de la Pedagogía pueden encontrarse algunos temas clásicos recurrentes en las investigaciones de los diferentes autores a lo largo de los siglos, que parecen no resolverse nunca o necesitar constantemente de nuevas miradas que permitan reinterpretar las mejores aproximaciones en un contexto sociohistórico cambiante, como indica Juan Luis Fuentes en el prólogo del libro.

Desde filósofos como Platón hasta nuestros días la educación moral ha estado presente en los escritos de muchos autores. Los enfoques y el peso que se le ha concedido han variado mucho entre las diferentes corrientes de pensamiento. Pero la relevancia para la articulación de las acciones educativas y su fundamentación en una determinada filosofía de la educación otorgan unas características singulares a la educación moral, como sigue explicando Fuentes.

Más allá del aprendizaje de contenidos y del desarrollo de habilidades, es tiempo oportuno de proponer una visión integral de la formación humana que considere todas las dimensiones de la persona, desde la moral e intelectual hasta la cívica e instrumental.

El libro recoge una colección de artículos de diversos autores publicados en la Revista Española de Pedagogía. Temas, que siguen siendo actuales, como el neutralismo predominante, la vinculación de la educación moral de manera exclusiva al ámbito religioso, etc. han sido tratados en un artículo de José Manuel Esteve Zaragaza.

Antonio Bolívar es el autor del segundo artículo presentado en el libro, en el que hace un minucioso análisis filosófico-pedagógico del enfoque moral adoptado en los años 80, vinculado a las teorías de Kohlberg y alejados de contenidos morales como la virtud, la norma y los ideales. Este modelo otorgó a la educación moral un papel más crítico con los códigos morales vigentes que de ocuparse en proponer uno concreto, tratando de impulsar hacia niveles superiores de razonamiento moral a los estudiantes así como de buscar coherencia entre el pensamiento y la conducta mediante el diálogo participativo.

El tercer artículo de María Victoria Gordillo realiza una crítica al modelo educativo-moral de Kohlberg con una perspectiva de la ética del cuidado y otros conceptos como la razón vital femenina.

Francisco Altarejos y Concepción Naval plantean en el cuarto artículo los problemas teóricos y prácticos de los derechos humanos y analizan sus fundamentos, 
indicando la dignidad y la libertad humanas como cuestiones esenciales de interés pedagógico.

El quinto artículo, de José Antonio Ibáñez-Martín, sitúa el foco sobre la promoción de la paz como contenido específico de la educación moral y de los profesores como constructores de la paz.

El penúltimo artículo, de María del Rosario González Martín y Juan Luis Fuentes, indica que la educación moral ha sido escasamente tratada en la investigación educativa en España. La experiencia humana fundamental del perdón se distingue de otros conceptos similares pedagógicos como la tolerancia, la asertividad y la solidaridad, para a continuación identificar una serie de pasos necesarios para aprender a perdonar, así como algunas estrategias educativas que lo facilitan.

Finalmente el profesor Pedro Ortega Ruiz defiende una ética de la alteridad, más contextualizada y centrada en el otro, en su sufrimiento y en la respuesta que necesita mediante el encuentro que evite posiciones acríticas colaboradoras de la desigualdad, la violencia y el etnocentrismo.

Todos los autores son exponentes de relieve en el área de la Pedagogía como muestran sus currículums vitae resumidos tras el Prólogo del libro electrónico, y sus artículos son un ejemplo de los trabajos publicados en la Revista Española de Pedagogía en las últimas décadas.

Mi reflexión es que la educación moral no debe estar al margen de los acontecimientos religiosos fundamentales (como son los testimonios y las enseñanzas católicas) que son origen y principio de la vida moral en todas sus dimensiones humanas, ni de la ética y la filosofía en que se basa toda sabia iniciativa educativa.

Mariano Ruiz Espejo Universidad Católica San Antonio de Murcia ruizesp@gmail.com 